\title{
Salutogenesis in Health Promoting \\ Settings: A Synthesis Across \\ Organizations, Communities, and Environments
}

\author{
Georg F. Bauer
}

\section{Introduction}

Settings are defined as "the place or social context in which people engage in daily activities in which environmental, organizational, and personal factors interact to affect health and well-being" (WHO, 1998). Such settings range from small-scale home/family to (international) organizations and large cities and thus differ in size, in their degree of formalized organization and their relationships to society.

The WHO Ottawa Charter for health promotion (1986) states that "health is created and lived by people within the settings of their everyday life; where they learn, work, play, and love" (emphasis added). Thus, this section focuses on how health is continuously promoted by everyday life in these settings and how health can be further enhanced through targeted interventions, leading to thriving settings and humans. This perspective is complementary to the section on healthcare settings that are explicitly in charge of dealing with health/disease. It is also complementary to the section on challenging social circumstances and environments that show how people can cope with and survive health-threatening situations.

In line with the salutogenic orientation, the WHO Ottawa Charter (1986), 35 years ago, clearly defined that health is a "...resource for everyday life .... A positive concept emphasizing social and personal resources, as well as physical capacities .... To reach a state of complete physical, mental, and social well-being." Surprisingly, later the WHO followed a more pathogenic orientation: "Healthy Settings, the settings-based approaches to health promotion, involve a holistic and multi-disciplinary method which integrates action across risk factors. The goal is to maximize disease prevention via a 'whole system' approach" (emphasis added)

\section{G. F. Bauer ( $\triangle)$}

Center of Salutogenesis, Division of Public and Organizational Health, Epidemiology, Biostatistics and Prevention Institute, University of Zürich, Zürich, Switzerland

e-mail: georg.bauer@uzh.ch
(WHO, 2015). The generic settings literature agrees upon several broader principles of the settings approach (Dooris, 2005, 2009; Paton et al., 2005; Poland et al., 2009; Shareck et al., 2013):

- Ecological model of health.

- Taking a whole systems approach considering reciprocal relationships within the system, between its subsystems, and its environment.

- Organizational development for change.

- Promoting participation as key process of interventions.

However, this generic literature makes no (Paton et al., 2005; Whitelaw et al., 2001) or only very brief general references to salutogenesis as a source of orientation for the settings approach (e.g., Dooris, 2005, 2009, 2013; Poland et al., 2009).

\section{Application of Salutogenesis in the Chapters in Part V}

The enclosed chapters review how salutogenesis has been applied to health promotion research and practice in a broad range of settings: organizations in general, schools, higher education, workplace, military settings, neighborhood/communities, cities, and restorative environments. Much of this setting-related literature is firmly rooted in general health promotion principles: interventions should be empowering, participatory, holistic, inter-sectorial, equitable, sustainable, and multi-strategy (Rootman, 2001).

However, in most cases, also this specific literature on single settings only loosely refers to salutogenesis. Some fields such as restorative environments or occupational health developed strong conceptual and empirical knowledge outside the salutogenic model - and the authors of the respective chapters show how these developments can be interpreted within the framework of salutogenesis. There is only limited research on specifying the sense of coherence 
and other elements of the salutogenic model (e.g., generalized resistance resources, salutary factors, ease-/dis-ease continuum) and their relationships for specific settings.

In contrast, research on designing interventions to promote salutogenesis actively is growing, for example, in the settings of neighborhoods, schools, worksites, or military settings. The following subsections identify key relationships between salutogenesis and settings emerging across these chapters.

\section{Overall Conceptual Relationships between Everyday Settings and Salutogenesis}

Most chapters agree that the general settings approach conceptually is in line with salutogenesis-as both imply not to target individuals and single risk factors or disease outcomes, but groups and upstream, environmental determinants of health and well-being. As everyday settings constitute key, influential life domains on the meso-level between the individual and the broader socioeconomic environment, the generalized resistance resources (GRRs) experienced in this context are expected to be a particularly strong source of the sense of coherence (SOC) of the members of the respective setting.

For the future, the settings approach could offer meaningful categories for classifying GRRs. GRRs can be specified by setting, for example, family, neighborhood, and work. Within a setting, subdimensions of GRRs can be identified based on key characteristics of the setting. Chap. 31 on work discriminates factual, task-related resources from relational, social resources. Chap. 33 on communities and neighborhoods distinguishes between settings as a place (natural and built environment), identity (sense of community), social entity (cohesion, social capital), and collective action (reactive-resilience; proactive-community action) - all meaningful categories of GRRs. Such clearly defined GRR categories would allow the study of their relative importance for developing the general SOC and a newer concept-a setting-specific SOC. The latter concept refers to the idea that each setting will vary regarding how comprehensible, manageable, and meaningful its members and customers perceive it. A person's setting-specific SOC will partly depend on her overall SOC. Her setting-specific SOC may also vary from setting to setting. For example, the setting-specific SOC may be quite strong in a person's educational setting and weaker in the same person's work setting. Following this line of reasoning, and inspired by previous developments like the family SOC, as an example we have developed and tested a work-related SOC scale (Bauer et al., 2015; Bauer \& Jenny, 2007; Vogt et al., 2013).

\section{Interrelationships between Settings from a Salutogenic Perspective}

The idea of setting-specific GRRs and SOC raises the interesting research question of how they influence each other across settings and how they differentially contribute to developing the generic SOC, health, and well-being. Whereas most of the enclosed chapters treat the various everyday settings separately, some reflect on such relationships between life domains.

Maass et al. show that SOC is influenced by different life domains (Maass et al., 2014): the satisfaction with the quality of neighborhood resources was significantly related to non-workers' and low-earners' SOC_-but not in employed persons. The authors conclude that deprived groups might benefit most from health promotion in neighborhoods-as they depend more on neighborhood quality. Research on restorative environments looks at the everyday variation of mostly ecological resources due to diverse personenvironment interactions during the day-considering both short-term effects on functioning and long-term, accumulative health effects of these cross-domain dynamics. It finds that work-related demands brought home by a person can constrain her recovery experience at home.

Research on the interface of work and non-work is of particular interest. It builds on several overarching theories potentially relevant to a better understanding of how GRRs positively influence health within and across settings. Research on the work/non-work relationship has moved from an originally heavily pathogenic focus on work-life conflicts to the more positive work-life enhancement processes and work-life balance as a positive outcome (Greenhaus and Allen, 2011). From a salutogenic perspective, the experience of balance could be understood as due to the successful balancing of stressors and GRRs across the involved life domains. Other promising theories relevant to a better understanding of GRRs include conservation of resource theory (Hobfoll, 1989, 2001), the work-home resource model (Brummelhuis \& Bakker, 2012), compensation theory, ecological systems theory, social identity theory, or spillover theory (Demerouti et al., 2012; Michel et al., 2009).

\section{Dynamics of the Development, Depletion, and Restoration of GRRs and SOC}

Antonovsky was especially interested in the long-term development of the SOC and the related role of GRRs. The chapters in Part $\mathrm{V}$ give insight into the challenges of making transitions to new life phases, shifts that might outpace the development of GRRs. Such transitions include entering the 
educational system or the job market, founding a family, or reaching retirement.

Several chapters also address the dynamics between GRRs, the SOC, and health. Research on restorative environments examines the daily "dynamics of depletion and renewal of resources needed for the maintenance and promotion of health and well-being" (Chap. 35, in this volume). It offers several theories explaining the restorative processes, such as the psychophysiological stress recovery theory and attention restoration theory. According to this theory, an environment is restorative if it is "rich in fascinating features, is perceived as coherently ordered and of substantial scope, and is compatible with what the individual wants to do" (Chap. 35, in this volume). These characteristics seem to overlap considerably with the SOC dimensions. Von Lindern, Lymeus, and Hartig point out that this theory could be of value in examining the suggestions that a weak SOC is due to initially too few GRRs and/or persistent deficiency in restoring overused GRRs.

In the work setting, the effort-recovery theory looks at the day-to-day dynamics of recovery from work-related stress through cognitive-emotional detachment from work. The job demands resource model that allows to study the dynamics of job resources, for example, by disentangling stable and changing parts of job resources over time (Brauchli et al., 2013) or by looking into reciprocal relationships of gain and loss cycles between job resources and health outcomes.

\section{Consider Positive Health Outcomes and a Path of Positive Health Development}

Chap. 5, "Aaron Antonovsky's Development of Salutogenesis, 1979-1994" (Vinje et al., this volume), shows that Antonovsky wanted to move beyond categorical disease outcomes by introducing the ease-/dis-ease continuum. However, he refrained from defining positive health, partly to avoid the medicalization of health and its potential misuse by power holders.

Still, most of the Part V chapters on everyday settings claim that considering positive health outcomes is one of the key criteria for classifying research and practice as salutogenic. As mentioned above, also the WHO Ottawa Charter (1986) defined health positively as "social and personal resources, as well as physical capacities .... to reach a state of complete physical, mental and social well-being." At the same time, most authors in this section agree that concrete measures of positive health outcomes are urgently needed. Chap. 30 on school settings proposes well-being, quality of life, control, action competence, and the ability to play and dance as positive health measures. Linking interventions to positive instead of disease outcomes is also considered to better resonate with people's positive goals in their everyday settings - a prerequisite for developing ownership of the interventions.

Chap. 35 on restorative environments shows that restoration can be promoted by "allowing people to become positively engaged with pleasantly interesting experiences in the moment ..." (emphasis added). Also, Chap. 31 on salutogenesis at work shows that the job demands resource model emphasizes a positive, motivational path from job resources to engagement as a positive outcome in its own right. The chapter illustrates how merging this logic with the generic health development model (Bauer et al., 2006) results in the job demands resource health model (Brauchli et al., 2015). This model suggests the simultaneous study of three parallel paths: job demands leading to disease outcomes (pathogenic path), job resources helping in coping with life stressors (original salutogenic coping path suggested by Antonovsky), and job resources leading directly to positive health outcomes (salutogenic path of positive health development).

\section{Social Relationships in Settings: Group-Level SOC in Settings}

Antonovsky's suggestion to conceptualize and measure the SOC on a group level has been repeated by several authors in Part V. As discussed in Chap. 5 in this book, Antonovsky proposed that SOC can be an emergent collective property in families, neighborhoods, and workgroups. He defined a group with a strong SOC as "a group whose individual members tend to perceive the collectivity as one that views the world as comprehensible, manageable, and meaningful... and ... a high degree of consensus in these perceptions" (Antonovsky, 1987, p. 174). He suggested several preconditions for the emergence of group SOC: sustained collectivity, group consciousness, overriding centrality of the group in members' lives, interwoven self-identity, and social identity. As key mechanisms, he suggested that groups with a strong SOC tend to structure situations that strengthen individual members' SOC and activate their collective resources.

As settings are defined as social systems, and as social relationships play a central role in their functioning, the idea of a group SOC could reasonably apply to settings. However, one needs to ask if postulating and measuring a group SOC adds additional power or meaning for explaining health development. At the very least, the concept of group-level health development processes deserves more attention. 


\section{Inclusion and Equity Perspective}

In Part V, several chapters point out that settings are spaces in which diverse groups can be present-facing quite diverse living situations. This implies considering differences in health development between groups in the same, shared setting with different cultural and socioeconomic backgrounds or life stages. At the same time, settings as shared social systems provide opportunities for linkages between and inclusion of such diverse groups, considering interdependencies across settings, for example, between working conditions, quality of family relationships, and quality of a neighborhood. Conceptually, such an inclusive perspective is promoted by the whole systems approach of settings as exemplified by whole schools or whole universities. From a salutogenesis perspective, this would imply studying differential, clustered opportunities for GRRs across various life domains and different levels of GRRs and setting-specific SOC for subgroups within settings.

\section{Salutogenesis Guiding Coherent Interventions in Settings}

Salutogenesis can guide interventions by pointing to GRRs, SOC, and positive health as key targets to be enhanced. At the same time, basic levels of GRRs and SOC are prerequisites to engage in the intervention process in the first place. Chap. 31 on work shows that a minimum level of job resources such as social support and recognition facilitates engaging in and benefitting from an intervention (Jenny et al., 2015). As pointed out in Chap. 35 on restorative environments, taking part in interventions by itself requires attention-for example, by acquiring new knowledge and skills. Thus, initially, interventions could be perceived as additional stressors and add to further depletion of attention resources.

Most chapters suggest participatory interventions to assure perceived relevance and ownership of the content of the intervention. To capture simultaneously potential negative and positive characteristics of the intervention process, one could ask participants about the intervention's comprehensibility, manageability, and meaningfulness. This intervention-related SOC has been applied in a large-scale stress intervention study in organizations and shown to be positively related to outcome expectancies of the intervention (Jenny et al., 2015). Bull et al. make a direct link between local development initiatives and SOC: "By mobilizing the capacity and assets of people and places, local development initiatives will make sense logically in the local context (comprehensibility), (...) practically realistic (manageability) and they will be motivating because they are meaningful, based on involvement in decision-making processes (meaningfulness)" (Bull et al., 2013, p. 171).

Further, most authors in Part V agree that linkages between the settings of interest and its broader, relevant environments need to be taken into account during interventions. These environments are sources of higher-order, upstream health determinants, and simultaneously contain external beneficiaries of health promotion interventions. Some chapters indicate that intervention success in one setting might depend on experiences in other settings. The case of community/neighborhoods shows that particularly people with lower-level jobs benefit from neighborhood interventions. Research on restorative environments, effortrecovery, and work-life balance suggests developing interventions to improve boundary crafting skills of people moving daily through their life domains to protect and restore key GRRs.

\section{Conclusions for Future Research and Practice}

The above synthesis demonstrates that applying salutogenesis to various settings and linking salutogenesis with other models established in these settings has the great potential to generate ideas on how to advance the general salutogenic model. First, it seems promising to study more the temporal and spatial dynamics of GRRs and SOC: short-term, daily changes, and relationships; relationships of GRRs and SOC across settings; changes of GRRs and SOC in life transitions. Second, specifying the salutogenic model for a specific setting allows one to select and study relationships among the elements of the salutogenic model that are particularly relevant to the setting's context. Third, the salutogenic model could guide interventions that by themselves are comprehensible, manageable, and meaningful, and thus directly strengthen the SOC. Fourth, everyday settings remind us that life is not only about surviving Antonovsky's “dangerous river of life." Instead, settings where people "learn, work, play, and love" are also about thriving. They is a key source of positive life experiences such as joy, growth, self-actualization, and flourishing - an emerging new research area that could lead to an expanded salutogenic model (Bauer et al., 2020).

\section{References}

Antonovsky, A. (1987). Unraveling the mystery of health: How people manage stress and stay well. Jossey-Bass.

Bauer, G. F., Davies, J. K., \& Pelikan, J. (2006). The EUHPID health development model for the classification of public health indicators. Health Promotion International, 21(2), 153-159.

Bauer, G. F., \& Jenny, G. (2007). Development, implementation and dissemination of occupational health management (OHM): Putting 
salutogenesis into practice. In S. McIntyre \& J. Houdmondt (Eds.), occupational health psychology. European perspectives on research, education and practice, Vol. 2, European academy of occupational health psychology (EA-OHP). Castelo da Maia: ISMAI.

Bauer, G. F., Vogt, K., Inauen, A., \& Jenny, G. J. (2015). Work-SoCEntwicklung und Validierung einer Skala zur Erfassung des arbeitsbezogenen Kohärenzgefühls. Zeitschrift für Gesundheitspsychologie, $55,115-131$

Bauer, G. F., Roy, M., Bakibinga, P., Contu, P., Downe, S., Eriksson, M., ... Mana, A. (2020). Future directions for the concept of salutogenesis: A position article. Health Promotion International, 35(2), 187-195.

Brauchli, R., Jenny, G. J., Füllemann, D., \& Bauer, G. F. (2015). Towards a job demands-resources health model: Empirical testing with generalizable indicators of job demands, job resources, and comprehensive health outcomes. BioMed Research International. https://doi.org/10.1155/2015/959621

Brauchli, R., Schaufeli, W. B., Jenny, G. J., Füllemann, D., \& Bauer, G. F. (2013). Disentangling stability and change in job resources, job demands, and employee Well-being-A three-wave study on the job-demands resources model. Journal of Vocational Behavior, 83(2), 117-129.

Brummelhuis, L. L., \& Bakker, A. B. (2012). A resource perspective on the work-home interface: The work-home resources model. American Psychologist, 67(7), 545-556.

Bull, T., Mittelmark, M., \& Kanyeka, N. E. (2013). Assets for Wellbeing for women living in deep poverty: Through a salutogenic looking-glass. Critical Public Health, 23(2), 160-173.

Demerouti, E., Peeters, M., \& van der Heijden, B. (2012). Work-family interface from a life and career stage perspective: The role of demands and resources. International Journal of Psychology, 47(4), 241-258.

Dooris, M. (2005). Healthy settings: Challenges to generating evidence of effectiveness. Health Promotion International, 21(1), 55-65.

Dooris, M. (2009). Holistic and sustainable health improvement: The contribution of the settings-bases approach to health promotion. Public Health, 129(1), 29-36.

Dooris, M. (2013). Expert voices for change: Bridging the silostowards healthy and sustainable settings for the 21 st century. Health \& Place, 20, 39-50.

Greenhaus, J. H., \& Allen, T. D. (2011). Work-family balance: A review and extension of the literature. In J. C. Quick \& L. E. Tetrick (Eds.), Handbook of occupational health psychology (pp. 165-183). American Psychological Association.
Hobfoll, S. (1989). Conversation of resources. A new attempt at conceptualizing stress. American Psychologist, 44(3), 513-524.

Hobfoll, S. (2001). The influence of culture, community, and the nestedself in the stress process: Advancing conservation of resources theory. Applied Psychology, 50(3), 337-421.

Jenny, G. J., Brauchli, R., Inauen, A., Füllemann, D., Fridrich, A., \& Bauer, G. (2015). Process and outcome evaluation of an organizational-level stress management intervention in Switzerland. Health Promotion International, 30(3), 573-585.

Maass, R. E. K., Lindstrøm, B., \& Lillefjell, M. (2014). Exploring the relationship between perceptions of neighbourhood-resources, sense of coherence and health for different groups in a Norwegian neighbourhood. Journal of Public Health Research, 3(1), 208.

Michel, J. S., Mitchelson, J. K., Kotrba, L. M., LeBreton, J. M., \& Baltes, B. B. (2009). A comparative test of work-family conflict models and critical examination of work-family linkages. Journal of Vocational Behavior, 74(2), 199-218.

Paton, K., Soumen, S., \& Lamiece, H. (2005). Settings, systems and organization development the healthy living and working model. Health Promotion International, 20(1), 81-89.

Poland, B., Kurpa, G., \& McCall, D. (2009). Settings for health promotion: An analytic framework to guide intervention design and implementation. Health Promotion Practice, 10(4), 505-516.

Rootman, I. (2001). Introduction. In I. Rootman et al. (Eds.), Evaluation in health promotion: Principles and perspectives. WHO.

Shareck, M., Frohlich, K. L., \& Poland, B. (2013). Reducing social inequities in health through settings-related interventions-A conceptual framework. Global Health Promotion 1757-9759, 20(2), $39-52$.

Vogt, K., Jenny, G. J., \& Bauer, G. (2013). Comprehensibility, manageability and meaningfulness at work: Construct validity of a scale measuring work-related sense of coherence. SA Journal of Industrial Psychology, 39(1), 8.

Whitelaw, S., Baxendale, A., Bryce, C., Machardy, L., Young, I., \& Witney, E. (2001). 'Settings' based health promotion: A review. Health Promotion International, 16(4), 339-353.

WHO. (1986). The Ottawa charter for health promotion-World 1986 http://www.who.int/healthpromotion/conferences/previous/ottawa/ en/ .

WHO. (1998). Health promotion glossary. WHO/HPR/HEP/98.1. Geneva.

WHO. (2015). Healthy settings. Retrieved September 24, 2015, from http://www.who.int/healthy_settings/en/.

Open Access This chapter is licensed under the terms of the Creative Commons Attribution 4.0 International License (http://creativecommons. org/licenses/by/4.0/), which permits use, sharing, adaptation, distribution and reproduction in any medium or format, as long as you give appropriate credit to the original author(s) and the source, provide a link to the Creative Commons license and indicate if changes were made.

The images or other third party material in this chapter are included in the chapter's Creative Commons license, unless indicated otherwise in a credit line to the material. If material is not included in the chapter's Creative Commons license and your intended use is not permitted by statutory regulation or exceeds the permitted use, you will need to obtain permission directly from the copyright holder. 